\title{
Fluorescent thiol-epoxy thermosets obtained from diglycidylether of bisphenol A and carbazole based diepoxy monomer
}

\author{
Oleksandra Korychenska ${ }^{\mathrm{a}, \mathrm{b}}$, Dailyn Guzmán ${ }^{\mathrm{a}}$, Àngels Serra ${ }^{\mathrm{a}, *}$, Xavier Ramis $^{\mathrm{c}}$, \\ Juozas V. Grazulevicius ${ }^{\mathrm{b}}$, \\ a Department of Analytical and Organic Chemistry, Universitat Rovira i Virgili, C/Marcellí Domingo s/n, 43007 Tarragona, Spain \\ b Department of Polymer Chemistry and Technology, Kaunas University of Technology, Radvilenu plentas 19, LT50254 Kaunas, Lithuania \\ c Thermodynamics Laboratory, ETSEIB Universitat Politècnica de Catalunya, Av. Diagonal 647, 08028 Barcelona, Spain
}

\section{A R T I C L E I N F O}

\section{Keywords:}

Carbazole

Cross-linking

Thermosets

Thiol-epoxy

Latency

\begin{abstract}
A B S T R A C T
A new epoxy resin containing carbazole moieties was synthesized and added in several proportions to diglycidylether of bisphenol A (DGEBA) and trimethylolpropane tris(3-mercaptopropionate) (TTMP) formulations that were thermally cured by thiol-epoxy click reaction. The curing was catalyzed by a latent amine precursor, which after triggering at high temperature liberates the amine that enables the formation of thiolate groups. The curing process of the different formulations was monitored by calorimetric analysis, which allowed to observe that the increase of the proportion of the synthesized epoxy resin with carbazole groups in the formulation decreased the curing rate. However, all these formulations cured quickly after triggering, which make them adequate for the formation of layers in multilayer devices.

Thermal characteristics of the obtained thermosets were determined by calorimetric, thermomechanical and thermogravimetric analysis. The obtained thermosets have good thermal stability. Their glass transition temperature increased when the proportion of the carbazole containing resin was increased in the formulation. The photophysical properties of the thermoset films were studied and it was proved that they exhibit fluorescence in the range of 352 to $369^{\circ} \mathrm{C}$.
\end{abstract}

\section{Introduction}

The multilayer structure of the devices of organic electronics such as organic light emitting diodes (OLEDs) is often created by solutionprocessing techniques such as spin coating, inkjet printing, etc. [1-3]. However, it is rather challenging to use solution processing methodologies, since intermixing of adjacent layers can occur if materials of the layers are soluble in the same solvents [4]. This requirement highly complicates selection of organic electroactive molecules intended for solution processed multilayer devices. A good approach to solve the problem of intermixing of adjacent layers is turning insoluble a layer onto which the upper layer is spin-coated or casted. This can be achieved via crosslinking of active compounds after deposition [5-8].

The use of a number of crosslinking techniques was reported over the years of research on OLEDs. Those techniques usually involve UV or thermal crosslinking reaction and these approaches were proved as useful tools for application on charge injecting, transporting, blocking and emitting layers of OLEDs [9-11]. Both polymers and monomer precursors were used for obtaining the crosslinked polymer films
[12-14]. Carbazole derivatives are widely used for the preparation of cross-linked electroactive layers, due to simplicity of introduction of reactive functional groups into carbazole moiety and due to valuable properties of carbazole derivatives, such as high hole-mobilities and high photoluminescence quantum yields $[11,12,14,15]$.

In the present work, the thermally activated click reaction between thiol and epoxy groups in the presence of amine was selected as an efficient method for the preparation of crosslinked networks with an immobilized chromophore. Thiol-epoxy thermosets are transparent and colorless materials, which can make possible their application in organic electronic devices. Moreover, thermosets based on thiols show the most ideal homogeneous network arrangement with narrow glass transition regions and extremely low polymerization shrinkage which reduces the stresses and defects in the final material. Because of its click character, thiol-epoxy reaction usually proceeds with high reaction rate and conversion under mild temperature conditions $[16,17]$. All of these characteristics make this type of materials attractive for applications in a variety of materials, such as coatings, adhesives, encapsulation materials and organic electronics [18].

\footnotetext{
* Corresponding authors.

E-mail addresses: angels.serra@urv.cat (À. Serra), juozas.grazulevicius@ktu.lt (J.V. Grazulevicius).
} 
Carbazole derivatives were extensively investigated for applications in different electronic devices $[19,20]$. The high level of interest in carbazole derivatives emerged due their hole transporting properties, strong absorption and efficient luminescence, good stability versus oxidation and easiness of carbazole derivatization [12,21-24].

In this paper, we explore the preparation of thermosets by means of click thiol-epoxy reaction between trimethylolpropane tris(3-mercaptopropionate) (TTMP), diglycidylether of bisphenol A (DGEBA) and a carbazole containing epoxy resin (9,9'-(1,4-phenylenebis\{oxy[2-(oxiran-2-yl-methoxy)propane-3,1-diyl]\})bis-9H-carbazole, named as HQCbz). Different formulations of DGEBA/HQ-Cbz with stoichiometric amounts of TTMP were tested to change the optical characteristics by varying the content of carbazole moieties in the material. The curing process was studied by differential scanning calorimetry and the thermal, thermomechanical and photophysical characteristics of the final thermosets were evaluated.

\section{Experimental}

\subsection{Materials}

( \pm )-Epichlorohydrin (ECH), trimethylopropane tris(3-mercaptopropionate) (TTMP), triethylamine (TEA) and hydroquinone (HQ) were purchased from Sigma-Aldrich and used without further purification. 9(2,3-epoxypropyl)carbazole (EPK) was purchased from Biolar (Latvia) and was twice recrystallized from isopropanol before using. Diglycidylether of bisphenol A (DGEBA, GY240, Huntsman, epoxy equivalent $182 \mathrm{~g} / \mathrm{eq}$ ) was dried at $80^{\circ} \mathrm{C}$ under vacuum for $6 \mathrm{~h}$. The amine precursor was Technicure ${ }^{\circledast}$ PDU-250 ( $N, N$-dimethyl phenyl urea) from AC Catalysts. All the organic solvents were purchased from Scharlab and were purified by standard procedures.

\subsection{Characterization}

${ }^{1} \mathrm{H}$ NMR spectra were recorded with a "Bruker Avance III " $\left(400 \mathrm{MHz}\left({ }^{1} \mathrm{H}\right), 100 \mathrm{MHz}\left({ }^{13} \mathrm{C}\right)\right)$ spectrometer in $\mathrm{CDCl}_{3}$ or DMSO- $d_{6}$ solutions. All the data are given as chemical shifts in $\delta(\mathrm{ppm})$, taken $\left(\mathrm{CH}_{3}\right)_{4} \mathrm{Si}$ as the internal standard.

FTIR spectra were recorded using Perkin Elmer Spectrum GX II FTIR System, equipped with attenuated total reflection (ATR) technique.

UV/Vis absorption spectra were recorded with an Avantes AvaSpec2048XL spectrometer. Photoluminescence spectra were recorded by Edinburgh Instruments FLS980 spectrometer with TMS300 monochromators and a red cooled detector (Hamamatsu R928P). Fluorescence quantum yields were measured using integrated sphere of a $120 \mathrm{~mm}$ inside diameter spherical cavity calibrated with two standards: quinine sulfate in $0.1 \mathrm{M} \mathrm{H}_{2} \mathrm{SO}_{4}$ and rhodamine $6 \mathrm{G}$ in ethanol. Clean quartz glass was used for the reference.

Calorimetric analyses were carried out on a Mettler DSC-821e or on a Mettler DSC-822e calorimeter. Samples (5-10 mg) were cured in aluminum pans in a nitrogen atmosphere $(100 \mathrm{~mL} / \mathrm{min})$. The calorimeter was calibrated using indium standard (heat flow calibration) and an indium-lead-zinc standard (temperature calibration).

In the dynamic curing process, the degree of conversion by DSC $\left(\alpha_{\text {DSC }}\right)$ was estimated as follows:

$\alpha=\frac{\Delta h T}{\Delta h d y n}$

where $\Delta h_{T}$ is the heat released up to a temperature $T$, obtained by integration of the calorimetric signal up to this temperature, and $\Delta h_{d y n}$ is the total reaction heat associated with the complete conversion of all reactive groups.

The linear integral isoconversional, model-free method of KissingerAkahira-Sunose (KAS) [25] was used for the determination of the activation energy based on the non-isothermal curing curves $\ln \left(\frac{\beta}{T^{2}}\right)=\ln \left(\frac{A \cdot R}{g(\alpha) \cdot E}\right)-\frac{E}{R T}$

where $\beta$ is the heating rate, $\mathrm{T}$ is the temperature, $E$ is the activation energy, $A$ is the pre-exponential factor, $\mathrm{R}$ is the gas constant, and $\mathrm{g}(\alpha)$ is the integral conversion function. For each conversion degree, the representation of $\ln \left(\beta / T^{2}\right)$ versus $1 / T$ produces a straight line and makes it possible to determine $E$ and $\ln [A R / g(\alpha) E]$ from the slope and the intercept without knowing the kinetic model. This non-isothermal kinetic study was performed in the temperature range from 50 to $300{ }^{\circ} \mathrm{C}$, with a heating rate of $2,5,10$ and $15^{\circ} \mathrm{C} \mathrm{min}-1$.

The thermal stability of the cured samples was determined by thermogravimetric analysis (TGA), using a Mettler TGA/SDTA 851e thermobalance. All the experiments were performed under nitrogen atmosphere at $100 \mathrm{~mL} / \mathrm{min}$. Pieces of the cured samples with an approximate mass of $8 \mathrm{mg}$ were subjected to the thermal degradation between 30 and $900{ }^{\circ} \mathrm{C}$ at a heating rate of $10^{\circ} \mathrm{C} / \mathrm{min}$.

Dynamic mechanical thermal analyses (DMTA) were carried out with a TA Instruments DMA Q800 analyzer. The samples for analysis were prepared by isothermal curing in a mold $\left(10 \times 7.6 \times 1.2 \mathrm{~mm}^{3}\right)$ at $120^{\circ} \mathrm{C}$ for $60 \mathrm{~min}$ and post-curing at $150{ }^{\circ} \mathrm{C}$ for $60 \mathrm{~min}$. The samples were cured isothermally in the mold $\left(10 \times 7.6 \times 1.2 \mathrm{~mm}^{3}\right)$ at $120^{\circ} \mathrm{C}$ during $1 \mathrm{~h}$ and then post-cured at $150{ }^{\circ} \mathrm{C}$ for $1 \mathrm{~h}$ and then carefully polished to ensure constant dimensions. The analysis was carried using 3-point bending clamp with support of span of $15 \mathrm{~mm}$. The viscoelastic properties of the cured materials were determined using $2{ }^{\circ} \mathrm{C} / \mathrm{min}$ heating rate from 30 to $120-180{ }^{\circ} \mathrm{C}$. The frequency was $1 \mathrm{~Hz}$ and the oscillation amplitude was of $10 \mu \mathrm{m}$.

\subsection{Synthesis}

\subsubsection{1,4-Di\{[3-(9-carbazolyl)-2-hydroxypropyl]oxy\} benzene (1)}

The synthesis was performed according to a previous publication [26]. In a two-necked flask equipped with reflux condenser and magnetic stirrer hydroquinone $(0.79 \mathrm{~g}, 7.2 \mathrm{mmol})$ and EPK $(3.9 \mathrm{~g}$, $17.5 \mathrm{mmol}$ ) in $50 \mathrm{~mL}$ of ethanol were heated to reflux temperature and then 10 drops of triethylamine were added and the mixture was kept at reflux for $12 \mathrm{~h}$. The precipitated product was filtered off and recrystallized from isopropanol. $\mathrm{T}_{\mathrm{m}}=167^{\circ} \mathrm{C}$ (determined by DSC).

${ }^{1} \mathrm{H}$ NMR (400 MHz, DMSO), $\delta$ in ppm: 8.0 (d, $J=7.7 \mathrm{~Hz}, 4 \mathrm{H}$ ), 7.39 (d, $J=8.1,4 \mathrm{H}), 7.34(\mathrm{~m}, 4 \mathrm{H}), 7.16(\mathrm{~m}, 4 \mathrm{H}), 6.7$ (s, 4H), 4.51 (dd, $J=14.5,6.1 \mathrm{~Hz}, 2 \mathrm{H}), 4.37-4.42(\mathrm{~m}, 4 \mathrm{H}), 3.85(\mathrm{dd}, J=9.3,4.1 \mathrm{~Hz}$, 2H), 3.77 (dd, $J=9.4,4.6 \mathrm{~Hz}, 2 \mathrm{H}$ ).

${ }^{13} \mathrm{C}$ NMR $\left(75.4 \mathrm{MHz}, \mathrm{CDCl}_{3}\right.$ ) $\delta$ in ppm: 45.6, 69.2, 78.1, 108.8, $115.7,119.4,120.4,123.1,126.0,140.7,152.8$.

\subsubsection{9,9'-(1,4-Phenylene bis\{oxy [2-(oxiran-2-yl methoxy)propane-3,1-} diyl]\})bis-9H-carbazole (HQ-Cbz)

In a $250 \mathrm{~mL}$ flask equipped with magnetic stirrer, compound 1 ( $2 \mathrm{~g}$, $3.6 \mathrm{mmol}$ ) was dissolved in $80 \mathrm{~mL}$ of butanone-2 (MEK). Afterwards, potassium hydroxide $(1.2 \mathrm{~g}, 21.6 \mathrm{mmol})$, anhydrous sodium sulfate $(1 \mathrm{~g}, 7.2 \mathrm{mmol})$ and epichlorohydrin $(5.6 \mathrm{~mL}, 71.8 \mathrm{mmol})$ were added to the solution. The mixture was stirred at $35{ }^{\circ} \mathrm{C}$ during $48 \mathrm{~h}$. After termination of the reaction (controlled by TLC, acetone:hexane, 1:2), inorganic residues were filtered off and the solvent was eliminated. HQCbz was recrystallized from ethanol and white crystals were obtained with the yield of $1.18 \mathrm{~g}(52 \%) . \mathrm{T}_{\mathrm{m}}=121{ }^{\circ} \mathrm{C}$, registered by DSC.

${ }^{1} \mathrm{H}$ NMR (400 MHz, $\mathrm{CDCl}_{3}$ ), $\delta$ in ppm: $8.10(\mathrm{~d}, J=7.7 \mathrm{~Hz}, 4 \mathrm{H}), 7.53$ (d, $J=7.7 \mathrm{~Hz}, 4 \mathrm{H}), 7.45(\mathrm{~m}, 4 \mathrm{H}), 7.24(\mathrm{t}, J=7.4 \mathrm{~Hz}, 4 \mathrm{H}), 6.84(\mathrm{~m}$, 4H), 4.59 (m, 4H), 4.20 (m, 2H), 4.03 (dd, $J=5.0,2.6 \mathrm{~Hz}, 2 \mathrm{H}), 3.97$ (m, 2H), 3.76 (dd, $J=11.9,3.0 \mathrm{~Hz}, 1 \mathrm{H}), 3.52(\mathrm{dd}, J=11.6,3.3 \mathrm{~Hz}$, $1 \mathrm{H}), 3.41(\mathrm{~m}, 2 \mathrm{H}), 2.90(\mathrm{~m}, 2 \mathrm{H}), 2.63(\mathrm{t}, J=4.4 \mathrm{~Hz}, 1 \mathrm{H}), 2.57$ (t, $J=4.4 \mathrm{~Hz}, 1 \mathrm{H}$ ), 2.48 (dd, $J=4.9,2.7 \mathrm{~Hz}, 1 \mathrm{H}), 2.32$ (dd, $J=4.9$, $2.7 \mathrm{~Hz}, 1 \mathrm{H})$.

${ }^{13} \mathrm{C}$ NMR (75.4 MHz, $\mathrm{CDCl}_{3}$ ): 153.0, 152.9, 140.8, 140.7, 126.0, 125.9, 123.0, 120.4, 120.3, 119.4, 119.3, 115.6, 109.2, 109.0, 78.1, 
Table 1

Composition of the formulations prepared in weight percentages.

\begin{tabular}{llll}
\hline $\begin{array}{l}\text { Formulation } \\
\text { HQ-Cbz:DGEBA }\end{array}$ & $\begin{array}{l}\text { Weight } \% \\
\text { HQ-Cbz }\end{array}$ & $\begin{array}{l}\text { Weight } \% \\
\text { DGEBA }\end{array}$ & $\begin{array}{l}\text { Weight \% } \\
\text { TTMP }\end{array}$ \\
\hline $50: 50$ & 32 & 32 & 36 \\
$60: 40$ & 39 & 26 & 35 \\
$70: 30$ & 47 & 20 & 33 \\
$80: 20$ & 54.5 & 13.8 & 31.7 \\
\hline
\end{tabular}

$72.1,71.3,69.6,69.1,68.1,67.7,50.8,50.1,45.6,44.8,44.7,44.3$, 44.2 .

ATR-FTIR, $\mathrm{cm}^{-1}$ : 3050 (w), 2875 (w), 1627 (w), 1595 (w), 1510 (m), 1485 (m), 1450 (m), 1327 (m), 1235 (w), 1116 (m), 1070 (m), 981 (m), $922(\mathrm{w}), 819(\mathrm{~m}), 746$ (s), 720 (s).

ESI-MS: $m / z 691.38[\mathrm{M}+\mathrm{Na}]^{+}$.

\subsection{Preparation of the reactive mixtures}

The mixtures were prepared by adding the required amount of HQCbz into the mixture of DGEBA epoxy resin and TTMP. Then, $2 \mathrm{phr}$ (parts per hundred of the mixture) of PDU-250 were added to the prepared formulations and the mixtures were homogenized by mechanical stirring with a spatula. Different mixtures with $50-80 \%$ (by weight) of HQ-Cbz with respect to DGEBA were prepared. Molar stoichiometric relation between epoxy and thiol groups (1:1) was kept for all the formulations. Table 1 collects the compositions of all the formulations studied.

\section{Results and discussion}

\subsection{Synthesis of the epoxy monomer}

The new biscarbazoyl epoxy resin was synthesized following a twostep procedure as represented in Scheme 1 . The first stage was an amine catalyzed nucleophilic attack of the phenolate derived from 1,4dihydroquinone on the less substituted carbon of glycidyl carbazole, according to an $\mathrm{S}_{\mathrm{N}} 2$ mechanism.

Hydroxyl groups can be transformed into glycidyl groups by the reaction with epichlorohydrin in excess in basic conditions. This method was previously applied to the preparation of epoxides [27]. The nucleophilic attack to the ECH occurs on the methylene carbon atom of the epoxy ring but not to the methylene carbon atom to which chlorine atom is attached. In this way, chlorohydrin groups can be produced as intermediate products, but the treatment with potassium hydroxide leads to its dehydrochlorination and to the production of glycidyl groups [28]. This procedure was applied for the synthesis of the similar carbazole derivatives and gave excellent results [29].

HQ-Cbz was characterized by ${ }^{1} \mathrm{H}$ and ${ }^{13} \mathrm{C}$ NMR spectroscopy. ${ }^{1} \mathrm{H}$ NMR spectrum is shown in Fig. 1.

The number of signals the ${ }^{1} \mathrm{H}$ NMR spectrum of HQ-Cbz is, in principle, higher than expected, but the presence of four stereocenters leads to the formation of the different diastereoisomers, which originate the splitting of the signals of the aliphatic protons and the aromatic signals assigned to hydroquinone nucleus. Four signals corresponding to the methylene protons of the glycidyl groups are splitted by the neighboring protons but also the signals are doubled because the formation of the above mentioned diastereoisomers. In contrast, the methine protons of the glycidyl group (signal at $2.9 \mathrm{ppm}$ ) appear overlapped. Methylene protons linked to carbazole nitrogen or to the oxygen of HQ group appear in the spectrum also splitted and doubled. The spectrum confirms the high purity of the compound and the absence of chlorohydrin groups.

The DSC analysis revealed that the newly synthesized resin exhibited melting in the first heating scan at $121^{\circ} \mathrm{C}$, and glass transition at $43^{\circ} \mathrm{C}$ in the second heating scan.

\subsection{Calorimetric study of the curing process}

The thiol-epoxy reaction was widely studied during the last years $[16,17]$. This process is base catalyzed, since base removes a proton from a thiol group increasing its nucleophilicity. Then, thiolate anion attacks the epoxide group forming the corresponding alkoxide that can further extract the thiol proton of another molecule. Usually, a tertiary amine is used as the base [17]. This reaction mechanism is represented in Scheme 2.

In general, the use of tertiary amines as catalysts for the thiol-epoxy reaction results in too high reactivity and, therefore, pot-life is too short for a safe application or storage [30]. This problem can be solved by the use of latent amine precursors which generate amine only when a certain high temperature is reached [30].

For this study, we chose as the latent catalyst commercially available $N, N$-dimethyl phenyl urea PDU-250. This compound has a melting point between 129 and $134^{\circ} \mathrm{C}$ (according to the supplier). After its melting point, urea decomposes to $N, N$-dimethylamine and phenyl isocyanate. This results in the activation of thiol-epoxy reaction at ca. $140{ }^{\circ} \mathrm{C}[18]$.

In order to prepare thermosets with carbazole moieties in the network structure, several thiol-epoxy formulations were tested in which different proportions of carbazole containing epoxy monomer (HQ-Cbz) were mixed with DGEBA. The stoichiometric amount of TTMP and $2 \mathrm{phr}$ of PDU-250 as the latent catalyst were added to the resin mixture. It should be noted, that the formulation containing the stoichiometric amount of TTMP and HQ-Cbz was not homogeneous and therefore, the addition of DGEBA was necessary in order to prepare homogeneous mixtures and finally to obtain homogeneous materials. In addition, the variation of the concentration of carbazole moieties in the final thermoset can result in different optical and thermomechanical differences.

Scheme 3 represents the type of network formed upon curing the thiol-epoxy mixture and includes the curing schedule selected for the thermosets preparation. However, the actual structure is apparently much more complicated since hydroxyl groups, formed after the reaction of epoxide with thiolate or present DGEBA, can also participate in the curing process. Alkoxides can extract thiol protons by an acidbase equilibrium but also, they can initiate homopolymerization of epoxide, which is favoured by a high hydroxyl content [31]. Nonetheless, due to the difference of pKa of the thiol/thiolate and hydroxyl/ alkoxide, the reaction between epoxy and thiol groups is preferable [32]. In previous studies in thiol-ene/thiol-epoxy stoichiometric mixtures it was confirmed by FTIR that thiol and epoxide disappeared completely and simultaneously, which confirmed that no epoxy homopolymerization occurred in these conditions [33].

The evolution of the curing process was investigated by non-
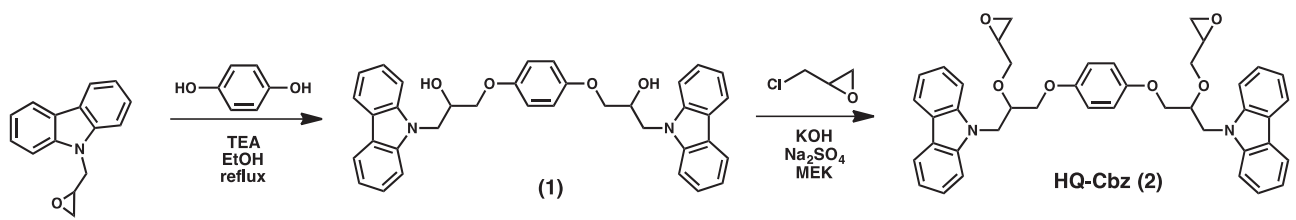

Scheme 1. Synthesis of epoxy monomer. 


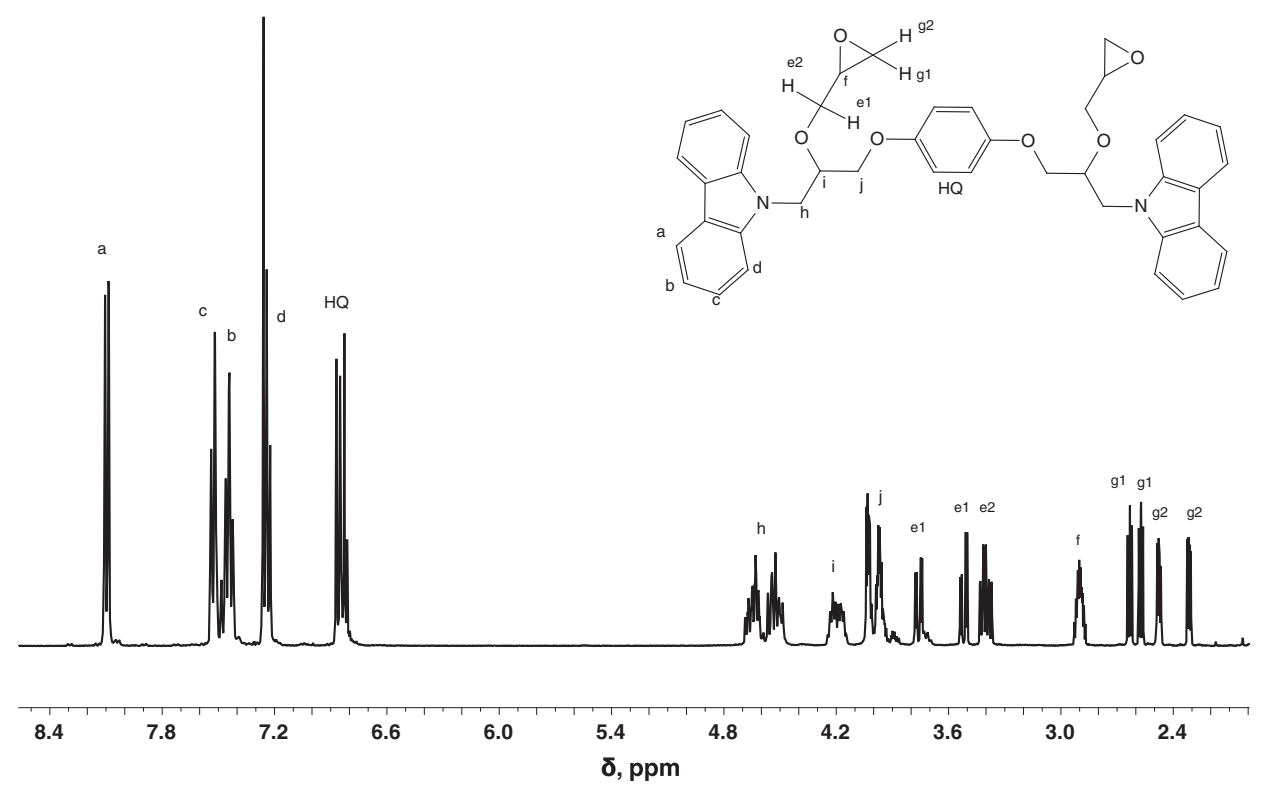

Fig. 1. ${ }^{1} \mathrm{H}$ NMR spectrum of the solution of HQ-Cbz in $\mathrm{CDCl}_{3}$.

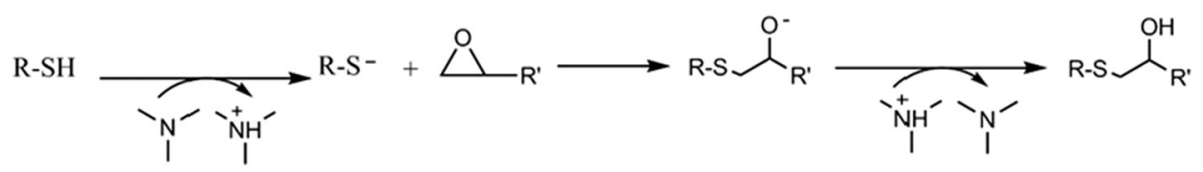

Scheme 2. Mechanism for the thiol-epoxy reaction.

isothermal differential calorimetry. Fig. 2 shows the DSC curing exotherms of four formulations with the different HQ-Cbz:DGEBA weight ratio. The increase in the amount of $\mathrm{HQ}-\mathrm{Cbz}$ in the formulation did not cause any significant changes in the curing temperature, but the curing rate increased with the increasing amount of DGEBA in the formulation. The latent character of PDU-250 allowed to initiate the curing process at the same temperature for all the formulations tested.

In Table 2 the calorimetric data of the curing process are collected. The reaction enthalpy released is mainly due to the opening of epoxy group, because of the strain relief. The values of the enthalpy measured per epoxy equivalent for all the formulations are approximately $106-110 \mathrm{~kJ} / \mathrm{Eq}_{\text {epoxy }}$, which indicates that practically complete curing was achieved [34]. However, on increasing the proportion of HQ-Cbz in the formulation the enthalpy per gram decreased due to the decrease of the amount of epoxy groups in the mixture.

From the calorimetric data and the evolution of curing it can be envisaged that the application of this type of curing reaction is highly adequate in the preparation of the layers of multilayer devices, since the reaction occurs quickly in a well-defined temperature range.

In order to understand the evolution of the curing, the isoconversional analysis was performed. The plots of conversion vs. temperature shown in Fig. 3 indicates that the reaction starts similarly for all the formulations, due to the latency of PDU-250. The slight decrease of the reaction rate for HQ-Cbz-rich formulations is observed after reaching $50 \%$ of conversion. This could be due to some differences in viscosity or because of the lower reactivity of aliphatic glycidyl ethers relative to that of the aromatic ones, according to their different electronic characteristics. In addition, the topological issues can affect differently the reactivity on changing the formulation composition. In Table 2 , the estimated reaction times required to reach a $80 \%$ of conversion are detailed. As we can see, there is a clear delay to reach this conversion on increasing the proportion of HQ-Cbz in the formulation.

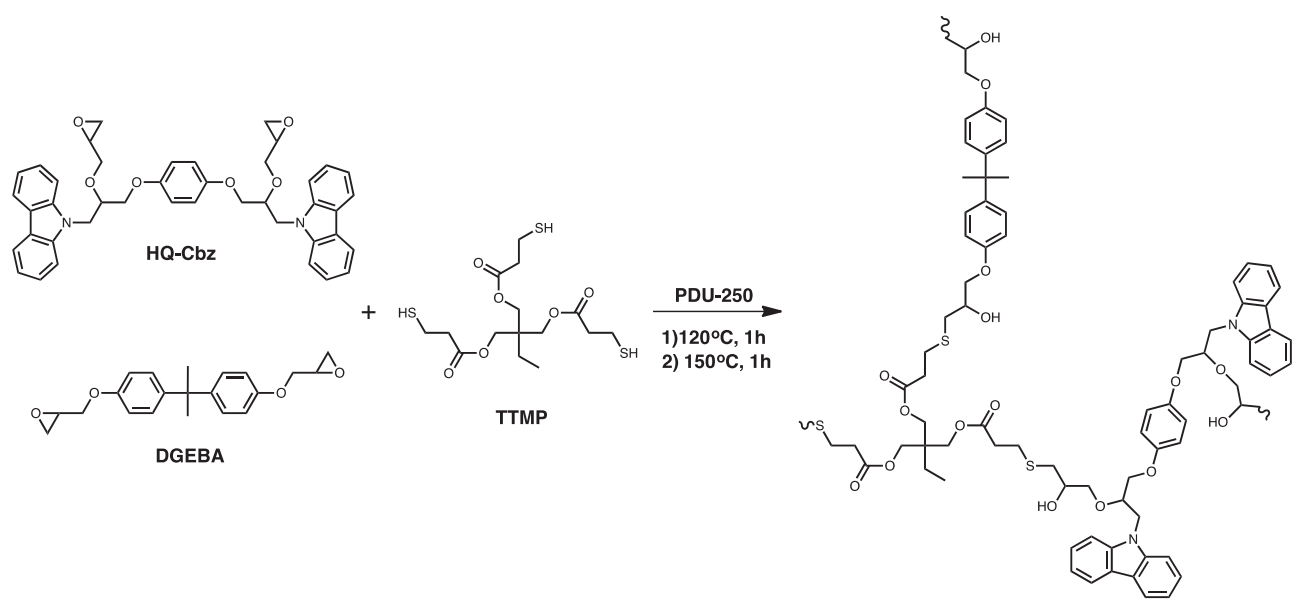

Scheme 3. Simplified structure of a fragment of the crosslinked thermoset. 


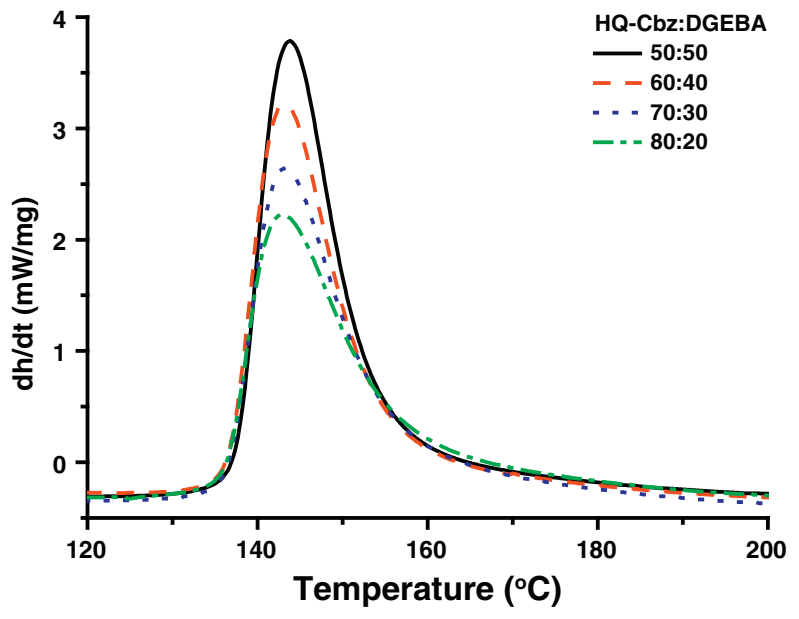

Fig. 2. Calorimetric curves recorded at $10{ }^{\circ} \mathrm{C} / \mathrm{min}$ of the mixtures HQ-Cbz/DGEBA in $\%$ $\mathrm{w} / \mathrm{w}$ with TTMP as the curing agent and PDU250 as the latent catalyst.

Table 2

Calorimetric data from the curing of the different formulations studied and $\mathrm{T}_{\mathrm{g}}$ of the thermosets obtained.

\begin{tabular}{llllll}
\hline $\begin{array}{l}\text { Formulation } \\
\text { HQ-Cbz:DGEBA }\end{array}$ & $\begin{array}{l}\Delta \mathrm{H}^{\mathrm{a}} \\
(\mathrm{J} / \mathrm{g})\end{array}$ & $\begin{array}{l}\Delta \mathrm{H}^{\mathrm{b}} \\
\left(\mathrm{kJ} / \mathrm{Eq}_{\text {epoxy }}\right)\end{array}$ & $\begin{array}{l}\mathrm{T}_{\max }{ }^{\mathrm{c}} \\
\left({ }^{\circ} \mathrm{C}\right)\end{array}$ & $\begin{array}{l}\mathrm{t}_{\text {80\%conv }}{ }^{\mathrm{d}} \\
(\mathrm{min})\end{array}$ & $\begin{array}{l}\mathrm{T}_{\mathrm{g}}{ }^{\mathrm{e}} \\
\left({ }^{\circ} \mathrm{C}\right)\end{array}$ \\
\hline $50: 50$ & 305 & 109 & 144 & 2.43 & 44 \\
$60: 40$ & 285 & 106 & 143 & 2.63 & 46 \\
$70: 30$ & 279 & 110 & 143 & 2.91 & 49 \\
$80: 20$ & 262 & 109 & 143 & 3.45 & 51 \\
\hline
\end{tabular}

${ }^{\text {a }}$ Enthalpy released during curing per gram of mixture.

${ }^{\mathrm{b}}$ Enthalpy released during curing per epoxy equivalent.

c Temperature of the maximum of the curing exotherm.

${ }^{\mathrm{d}}$ Estimated reaction time to reach $80 \%$ of conversion.

e Glass transition temperature, determined by DSC.

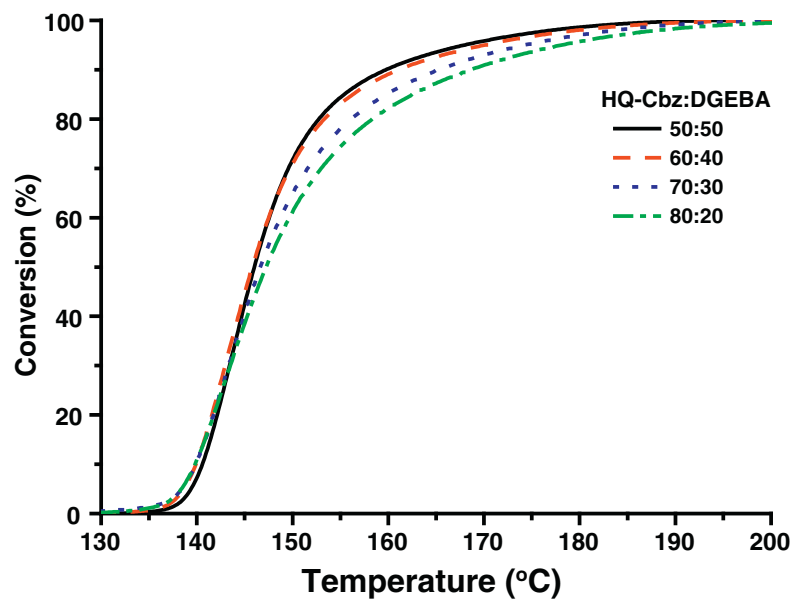

Fig. 3. Conversion degrees against temperature for the curing of the formulations studied with different HQ-Cbz:DGEBA weight ratios obtained by DSC by heating at $10{ }^{\circ} \mathrm{C} / \mathrm{min}$.

Fig. 4 shows the variation of the activation energies against conversion for the curing of the formulations studied. There are no great differences among them, according to the DSC traces showed in Figs. 2 and 3, but the increase of the HQ-Cbz proportion in the formulation slightly reduces the energy value. This reduction seems not agree with the slight decelerative effect observed, but the compensation effect between activation energy and the pre-exponential factor must be considered [35]. The kinetic results obtained by combination of the activation energy and the second kinetic parameter $\ln [\mathrm{AR} / \mathrm{g}(\alpha) \mathrm{E}]$ (data do not shown) of the isoconversional method are consistent with the kinetic effect exerted by HQ-Cbz on curing, especially at high

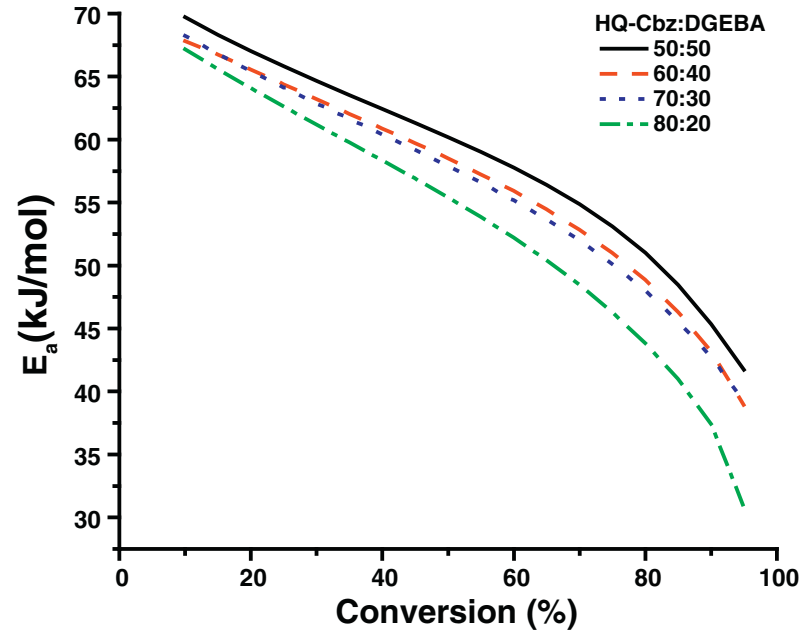

Fig. 4. Activation energy versus degree of conversion for the mixtures with the different ratios of HQ-Cbz and DGEBA.

conversions (see values in Table 2). The significant reduction of the activation energy is observed when the curing process advances. At the beginning of curing the release of active amine and the formation of the thiolate anion control the kinetics of the reaction, showing a higher activation energy, which decreases due to the autocatalytic behaviour of thiol-epoxy curing in the presence of the tertiary amines [32,36]. A similar reduction of the activation energy during curing was also observed for the system DGEBA/trithiol using PDU-250 as the latent catalyst [30].

The glass transition temperatures $\left(\mathrm{T}_{\mathrm{g}}\right)$ of the cured samples (see Table 2) were determined after two consecutive dynamic scans at $10{ }^{\circ} \mathrm{C} / \mathrm{min}$ starting at $-50{ }^{\circ} \mathrm{C}$ to eliminate the thermal history. The value of $\mathrm{T}_{g}$ of the materials slightly increased with the increase of the amount of HQ-Cbz in the formulation. This observation can be explained by the lower amount of flexible thiol fragments in the formulations containing higher amount of HQ-Cbz and/or by the higher amount of carbazolyl groups that can create $\pi-\pi$ interactions. Both phenomena reduce the flexibility of the network. Thiol-epoxy thermosets usually exhibit rather low $\mathrm{T}_{g}$ due to the introduction of flexible fragments of the thiol used and also due to the enhanced flexibility of thioether units, as the consequence of the longer $\mathrm{S}-\mathrm{C}$ bond $(1.8 \AA)$ versus the $\mathrm{C}-\mathrm{C}$ bond $(1.2-1.5 \AA$ ). Increasing the functionality of the comonomers or introducing rigid moieties in their structure is a good strategy of reaching higher $\mathrm{T}_{\mathrm{g}} \mathrm{s}$ [37].

\subsection{Thermal characterization of thermosets}

The thermal stability of the thermosets prepared was studied by thermogravimetric analysis. The thermal schedule was optimized to reach a complete curing and was performed as explained in the experimental part. The differential TGA curves shown in Fig. 5 reveal the excellent thermal stability of these materials with one main step of decomposition and a little shoulder at high temperatures, which seems to become more important on increasing the amount of HQ-Cbz in the material.

The main data of the thermogravimetric analysis are collected in Table 3. The degradation process starts at similar temperatures for all the formulations studied and only little differences are observed in the temperature of the maximum degradation rate.

The thermomechanical characteristics of the thermosets were performed and the temperatures of the maximum of $\tan \delta$ are collected in Table 3. The temperature of the $\alpha$ relaxation shows the same trend as $\mathrm{T}_{\mathrm{g}}$ determined by DSC on changing the composition, with a slight increase on increasing the proportion of HQ-Cbz in the material. The values of $\mathrm{T}_{\mathrm{g}}$ obtained from DMTA are higher than those obtained from 


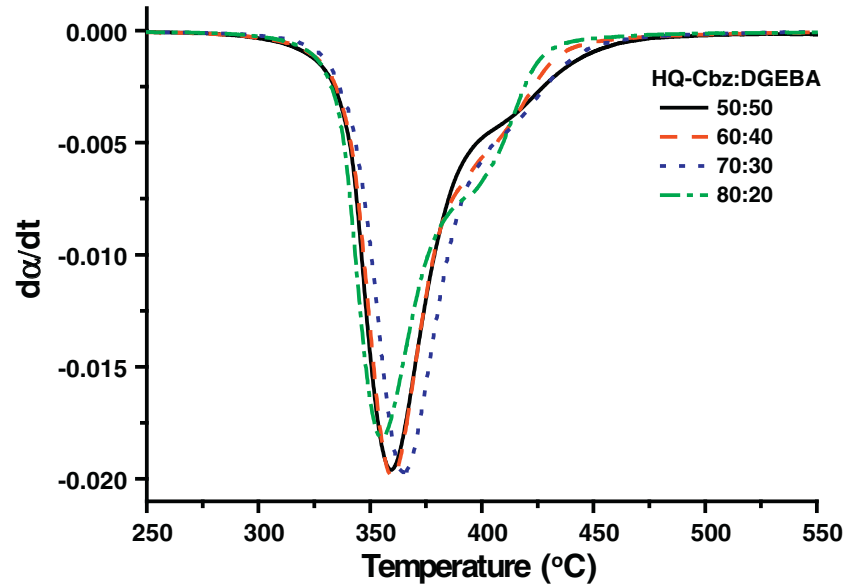

Fig. 5. Differential TGA curves at $10{ }^{\circ} \mathrm{C} / \mathrm{min}$ in $\mathrm{N}_{2}$ atmosphere of the thermosets prepared from the different HQ-Cbz:DGEBA formulations.

Table 3

Thermogravimetric data and $\tan \delta$ temperature value for the different thermosets.

\begin{tabular}{llll}
\hline $\begin{array}{l}\text { Formulation } \\
\text { HQ-Cbz:DGEBA }\end{array}$ & \multicolumn{2}{c}{$\mathrm{TGA}$} & DMTA \\
\cline { 2 - 3 } & $\begin{array}{l}\mathrm{T}_{5 \%} \\
\left({ }^{\circ} \mathrm{C}\right)^{\mathrm{a}}\end{array}$ & $\begin{array}{l}\mathrm{T}_{\max } \\
\left({ }^{\circ} \mathrm{C}\right)^{\mathrm{b}}\end{array}$ & $\begin{array}{l}\mathrm{T}_{\tan \delta} \\
\left({ }^{\circ} \mathrm{C}\right)^{\mathrm{c}}\end{array}$ \\
\hline $50: 50$ & 335 & 359 & 61 \\
$60: 40$ & 336 & 360 & 64 \\
$80: 30$ & 336 & 359 & 64 \\
\hline 0020 & 336 & 355 & 67 \\
\hline
\end{tabular}

a Temperature of the onset decomposition on TGA data at $10{ }^{\circ} \mathrm{C} / \mathrm{min}$ calculated for $5 \%$ weight loss.

b Temperature of maximum decomposition rate based on the TGA data at $10{ }^{\circ} \mathrm{C} / \mathrm{min}$.

c Temperature of the maximum of $\tan \delta$.

Table 4

Photophysical characteristics of the thermosets.

\begin{tabular}{lllll}
\hline Sample & $\lambda_{\max }{ }^{U V}, \mathrm{~nm}^{\mathrm{a}}$ & $\lambda_{\max }{ }^{F L}, \mathrm{~nm}^{\mathrm{b}}$ & Stokes Shift, $\mathrm{nm}^{\mathrm{c}}$ & $\Phi_{\mathrm{FL}},{ }^{\mathrm{d}}$ \\
\hline Neat HQ-Cbz1 & 346 & 351 & 5 & 10.19 \\
$50: 50$ & 347 & $352 / 368$ & 5 & 4.34 \\
$60: 40$ & 345 & $352 / 369$ & 7 & 4.19 \\
$70: 30$ & 347 & $352 / 368$ & 5 & 6.38 \\
$80: 20$ & 347 & $352 / 367$ & 5 & 4.61 \\
\hline
\end{tabular}

a - UV-VIS spectra of thin films;

b - FL spectra of thin films;

c - Stokes shift calculated using equation: Stokes shift $=\lambda_{\max }{ }^{F L}-\lambda_{\max }{ }^{U V}$;

d $-\Phi_{\mathrm{FL}}-$ fluorescence quantum efficiency determined for thin films with a pure quartz glass as a reference, $\lambda_{\mathrm{ex}}=290 \mathrm{~nm}$.
DSC measurements, because of the different frequencies used in both studies.

\subsection{Optical and photophysical characterization of thermosets}

All the thermosets prepared showed absorption in the near-ultraviolet region $(200-400 \mathrm{~nm})$. The absorption bands correspond to the typical pattern reported for $\mathrm{N}$-substituted carbazole compounds. The absorption band at 345-347 $\mathrm{nm}$ can be assigned to $\mathrm{n} \rightarrow \pi^{*}$ transition. The intensive band at $298 \mathrm{~nm}$ is characteristic for $\pi \rightarrow \pi^{*}$ transition and the band at the high energy region $(265 \mathrm{~nm})$ is assigned to $n \rightarrow \sigma^{*}$ transition (Table 4 and Fig. 6) [38].

All the thermosets exhibit the structured fluorescence characteristic of $\mathrm{N}$-alkyl carbazole moieties with a strong $(0,0)$ band at $c a$ 351-352 nm (Fig. 6). However, the structure is less expressed in the spectrum of the monomer. The intensity of the tail extending to the lower energies rises with the increase of the concentration of the chromophore in the samples. Thus, it could mean that formation of excimers occurs.

Fluorescence quantum yields for the films of the thermosets and the monomer are not higher than $10 \%$. The highest quantum yield is shown by the neat monomer. These values of fluorescence quantum yields are comparable with those of the solid samples of other carbazole derivatives $[39,40]$. The low values of fluorescence quantum yields could be due to partial reabsorption of emitted light, because of overlapping of the absorption and emission bands of the material. The other possible reason of rather low fluorescence quantum yields is aggregation induced quenching.

\section{Conclusions}

New carbazole containing epoxy resin (HQ-Cbz) was synthesized from 1,4-di\{[3-(9-carbazolyl)-2-hydroxypropyl]oxy\}benzene by the reaction of the hydroxyl groups in its structure with epichlorohydrin.

HQ-Cbz was mixed in different proportions with diglycidylether of bisphenol A (DGEBA) and the mixtures were cured by a thiol-epoxy click reaction, using trimethylopropane tris(3-mercaptopropionate) as the curing agent. $\mathrm{N}, \mathrm{N}$-dimethyl phenyl urea (PDU-250) was used as a latent amine precursor. The curing temperature did not depend on the ratio of the components, since it started when the amine was released. The curing rate increased on increasing the proportion of DGEBA in the formulation. The practical full conversion of epoxy groups was achieved.

The glass transition temperatures of the obtained thermosets increased with the increase of the amount of carbazole moieties in the material. The thermosets possess excellent thermal stability. The temperatures of $5 \%$ mass loss were $335-336{ }^{\circ} \mathrm{C}$.

The thermosets absorb radiation in the near-UV region and exhibit fluorescence with intensity maxima in the range of $352-369^{\circ} \mathrm{C}$. The fluorescence quantum yields are lower than $10 \%$.

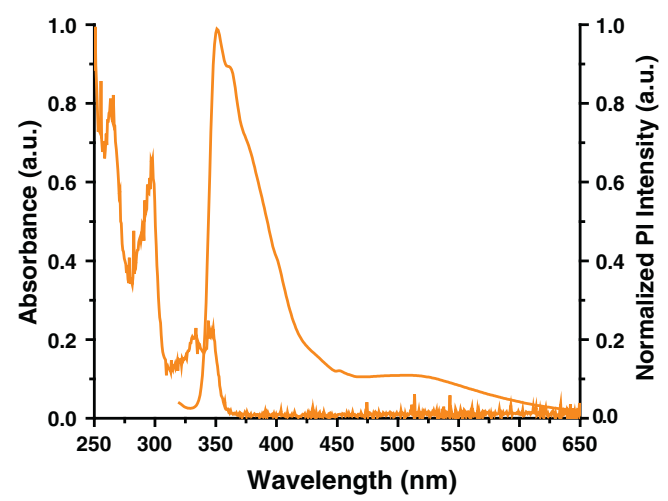

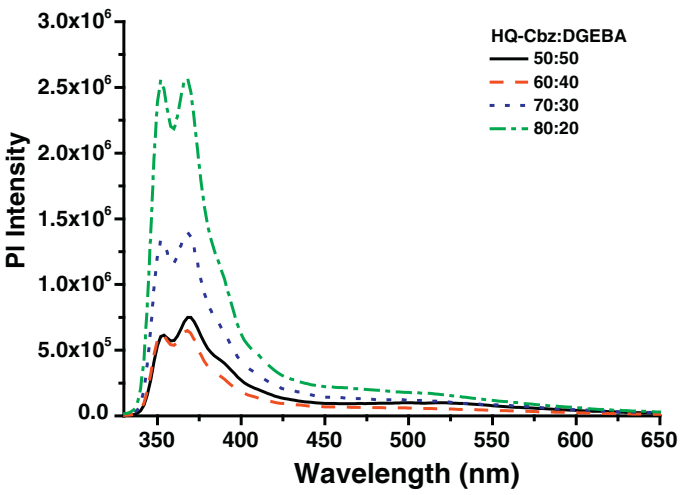

Fig. 6. Absorption and fluorescence spectra $\left(\lambda_{\mathrm{ex}}=290 \mathrm{~nm}\right)$ of the films of the HQ-Cbz (left) and fluorescence spectra of thermosets (right). 


\section{Acknowledgments}

The authors would like to thank MINECO (MAT2014-53706-C0301, MAT2014-53706-C03-02) and Generalitat de Catalunya (2014-SGR67) for giving the financial support. This research was also partially supported by the Research Council of Lithuania (project No TAP LLT-2/ 2017). Dr. Mykola Bezuglyi is thanked for his help in the photophysical measurements.

\section{References}

[1] O. Nuyken, S. Jungermann, V. Wiederhirn, E. Bacher, K. Meerholz, Modern trends in organic light-emitting devices (OLEDs), Monatshefte Fur Chemie 137 (2006) 811-824.

[2] H. Gorter, M.J.J. Coenen, M.W.L. Slaats, M. Ren, W. Lu, C.J. Kuijpers, W.A. Groen, Toward inkjet printing of small molecule organic light emitting diodes, Thin Solid Films 532 (2013) 11-15.

[3] B.M. Singh, H.M. Haverinen, P. Dhagat, G.E. Jabbour, Inkjet printing — process and its applications, Adv. Mater. 22 (2010) 673-685.

[4] D.M. Small, W.Y. Sanchez, M.J. Hickey, G.C. Gobe, Review of recent progress in multilayer solution-processed organic light-emitting diodes, J. Photonics Energy 5 (2015) 57611.

[5] N. Riegel, J.H.M. Kremer, H. Lademann, K. Meerholz, D.C. Mu, The simple way to solution-processed multilayer OLEDs - layered block-copolymer networks by living cationic polymerization, Adv. Mater. 21 (2009) 879-884.

[6] B.L. Diodes, L. Diodes, P. Zacharias, M.C. Gather, M. Rojahn, O. Nuyken, K. Meerholz, New Crosslinkable hole conductors for blue-phosphorescent organic, Angew. Chem. Int. Ed. 46 (2007) 4388-4392.

[7] N. Du, R. Tian, J. Peng, Q. Mei, M. Lu, Cross-linked Alq 3 -containing polymers with improved electroluminescence efficiency used for OLEDs, Macromol. Rapid Commun. 27 (2006) 412-417.

[8] C.A. Zuniga, S. Barlow, S.R. Marder, Approaches to solution-processed multilayer organic light-emitting diodes based on cross-linking, Chem. Mater. 23 (2011) 658-681.

[9] W.-Y. Hung, C.-Y. Lin, T.-L. Cheng, S.-W. Yang, A. Chaskar, G.-L. Fan, K.-T. Wong, T.-C. Chao, M.-R. Tseng, A new thermally crosslinkable hole injection material for OLEDs, Org. Electron. 13 (2012) 2508-2515.

[10] B.J. Kim, Y. Miyamoto, B. Ma, J.M.J. Fréchet, Photocrosslinkable polythiophenes for efficient, thermally stable, organic photovoltaics, Adv. Funct. Mater. 19 (2009) 2273-2281.

[11] M.S. Liu, Y. Niu, J. Ka, H. Yip, F. Huang, J. Luo, T. Kim, A.K. Jen, Thermally crosslinkable hole-transporting materials for improving hole injection in multilayer blueemitting phosphorescent polymer light-emitting diodes, Macromolecules 41 (2008) 9570-9580.

[12] P. Czub, W. Mazela, J. Pielichowski, Epoxy-carbazole compositions, Synth. Met. 158 (2008) 826-830.

[13] A.R. Davis, K.R. Carter, Controlling optoelectronic behavior in poly(fluorene) networks using thiol-Ene photo-click chemistry, Macromolecules 48 (2015) 1711-1722.

[14] S. Grigalevicius, B. Zhang, Z. Xie, M. Forster, U. Scherf, Polycarbazole-based networks made by photo-crosslinking for hole transporting layers of OLED devices, Org. Electron. 12 (2011) 2253-2257.

[15] Y. Tang, J. Zhuang, L. Xie, X. Chen, D. Zhang, Thermally cross-linkable host materials for solution-processed oleds: synthesis, characterization, and optoelectronic properties, Eur. J. Org. Chem. 22 (2016) 3737-3747.

[16] S. De, A. Khan, Efficient synthesis of multifunctional polymers via thiol-epoxy "click" chemistry, Chem. Commun. 48 (2012) 3130-3132.

[17] C.E. Hoyle, A.B. Lowe, C.N. Bowman, Thiol-click chemistry: a multifaceted toolbox for small molecule and polymer synthesis, Chem. Soc. Rev. 39 (2010) 1355.

[18] O. Korychenska, C. Acebo, M. Bezuglyi, A. Serra, J.V. Grazulevicius, Epoxy-thio thermosets modified by carbazole decorated hyperbranched poly(ethyleneimine) for optical applications, React. Funct. Polym. 106 (2016) 86-92.

[19] K.R.J. Thomas, J.T. Lin, Y. Tao, C. Ko, Light-emitting Carbazole derivatives potential electroluminescent materials, J. Am. Chem. Soc. 123 (2001) 9404-9411.

[20] J.V. Grazulevicius, P. Strohriegl, J. Pielichowski, K. Pielichowski, Carbazolecontaining polymers: synthesis, properties and applications, Prog. Polym. Sci. 28 (2003) 1297-1353.

[21] T. Malinauskas, V. Gaidelis, V. Jankauskas, V. Getautis, Novel highly soluble 3,3'bicarbazolyl based polymers for optoelectronics, Eur. Polym. J. 44 (2008) 3620-3627.

[22] S.M. Bonesi, R. Erra-Balsells, Electronic spectroscopy of carbazole and N- and Csubstituted carbazoles in homogeneous media and in solid matrix, J. Lumin. 93 (2001) 51-74.

[23] B. Mailhot-Jensen, S. Robu, A. Rivaton, J.-F. Pilichowski, A. Chirita, E. Chilat, G. Dragalina, Carbazole containing copolymers: synthesis, characterization, and applications in reversible holographic recording, Int. J. Photoenergy 2010 (2010) $1-11$.

[24] J.-F. Morin, M. Leclerc, D. Adès, A. Siove, Polycarbazoles: 25 years of progress, Macromol. Rapid Commun. 26 (2005) 761-778.

[25] S. Vyazovkin, A.K. Burnham, J.M. Criado, L.A. Pérez-Maqueda, C. Popescu, N. Sbirrazzuoli, ICTAC kinetics committee recommendations for performing kinetic computations on thermal analysis data, Thermochim. Acta 520 (2011) 1-19.

[26] S. Grigalevicius, J. Ostrauskaite, J.V. Grazulevicius, V. Gaidelis, V. Jankauskas, J. Sidaravicius, Cross-linkable photoluminescent hole-transporting molecular glasses, Mater. Chem. Phys. 77 (2003) 281-284.

[27] E. Andrikaityte, M. Cekaviciute, J. Simokaitiene, G. Buika, J. Vidas, V. Rubeziene, Reactive \& functional polymers glass-forming 1, 3-bis ( carbazol-9-yl ) propan-2-ol based monomers and polymers, React. Funct. Polym. 72 (2012) 11-16.

[28] J. Clayden, N. Greeves, S. Warren, P. Wothers, Organic Chemistry, Oxford University Press, Oxford, 2000.

[29] G. Bubniene, T. Malinauskas, V. Getautis, A. Stanisauskaite, V. Jankauskas, J. Sidaravicius, Synthesis of new hole-transporting molecular glass with pendant carbazolyl moieties, Synth. Met. 158 (2008) 670-675.

[30] D. Guzmán, X. Ramis, X. Fernández-francos, A. Serra, New catalysts for diglycidyl ether of bisphenol A curing based on thiol - epoxy click reaction, Eur. Polym. J. 59 (2014) 377-386.

[31] X. Fernández-Francos, W.D. Cook, À. Serra, X. Ramis, G.G. Liang, J.M. Salla, Crosslinking of mixtures of DGEBA with 1,6-dioxaspiro[4,4]nonan-2,7-dione initiated by tertiary amines. Part IV. Effect of hydroxyl groups on initiation and curing kinetics, Polymer (Guildf) 51 (2010) 26-34.

[32] X. Fernández-Francos, A.-O. Konuray, A. Belmonte, S. De la Flor, À. Serra, X. Ramis, Sequential curing of off-stoichiometric thiol-epoxy thermosets with a customtailored structure, Polym. Chem. 7 (2016) 2280-2290.

[33] D. Guzmán, X. Ramis, X. Fernandez-Francos, À. Serra, Preparation of click thiolene/thiol-epoxy thermosets by controlled photo/thermal dual curing sequence, RSC Adv. 5 (2015) 101623-101633.

[34] B. Rozenberg, Kinetics, thermodynamics and mechanism of reactions of epoxy oligomers with amines, Epoxy Resins Compos. II. 75 (1986) 113-165.

[35] S. Vyazovkin, C.A. Wight, Kinetics in solids, Annu. Rev. Phys. Chem. 48 (1997) $125-149$.

[36] R.M. Loureiro, T.C. Amarelo, S.P. Abuin, E.R. Soulé, R.J.J. Williams, Kinetics of the epoxy-thiol click reaction initiated by a tertiary amine: calorimetric study using monofunctional components, Thermochim. Acta 616 (2015) 79-86.

[37] D. Guzmán, X. Ramis, X. Fernández-Francos, A. Serra, Enhancement in the glass transition temperature in latent thiol-epoxy click cured thermosets, Polymers (Basel) 7 (2015) 680-694.

[38] G.E. Johnson, Emission properties of vinylcarbazole polymers, J. Chem. Phys. 62 (1975) 4697-4709.

[39] D. Gudeika, J. Vidas, D. Volyniuk, R. Butkute, G. Juska, A. Miasojedovas, A. Gruodis, S. Jursenas, Structure-properties relationship of the derivatives of carbazole and 1,8-naphthalimide: effects of the substitution and the linking topology, Dyes Pigments 114 (2015) 239-252.

[40] M. Gong, J. Cha, C. Won, Synthesis and device properties of $\mathrm{mCP}$ analogues based on fused-ring carbazole moiety, Org. Electron. 42 (2017) 66-74. 